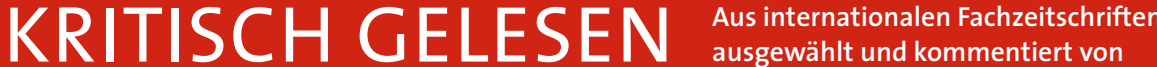

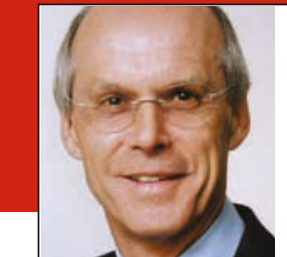

Prof. Dr. med. H. S. FüeßI Isar-AmperKlinikum, KI. MünchenOst, Haar

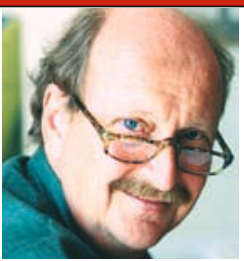

Prof. Dr. med. E. Ernst

Peninsular

Medical School,

University

of Exeter/UK

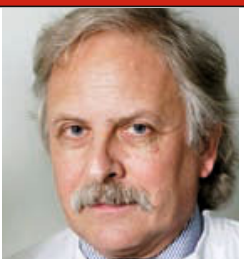

Prof. Dr. med. H.-C. Diener

Neurologie, Universitätsklinik Essen

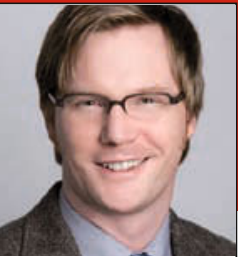

Dr. med. F. C. Ringshausen Pneumologie, Zürich

\section{Übergewicht als Zirrhose-Risiko}

Unter dem Eindruck der Adipositaswelle in den westlichen Industrieländern ändert sich die Ätiologie der Leberzirrhose: Zumindest bei Frauen spielt neben dem Alkohol auch das Übergewicht eine zunehmende Rolle.

— In der Million-Women-Study, einer prospektiven Kohortenstudie an 1,3 Mio. Frauen, die am Brust-ScreeningProjekt des nationalen Gesundheitsdienstes in England und Schottland teilnehmen, erhielt man gesundheitsbezogene Daten von 1,2 Mio. Frauen. Beim Eintritt in die Studie waren sie im Durchschnitt 56 Jahre alt und konnten über einen Zeitraum von durchschnittlich 6,2 Jahren nachuntersucht werden.

Neben der Dokumentation der medizinischen Basisdaten füllten die Frauen im Abstand von drei bis vier Jahren Fragebögen aus, in denen sie u.a. auch Auskünfte über ihren Alkoholkonsum gaben.

Aus den Diagnosestatistiken von Krankenhäusern extrahierte man Daten zur stationären Behandlung und Tod wegen/an Leberzirrhose. Im Nachbeobachtungszeitraum wurden 1811 Frauen erstmals wegen Leberzirrhose stationär behandelt oder starben daran. Dabei fand sich eine Assoziation zwischen der
Zunahme des Bodymass-Index und einer erhöhten Inzidenz von Leberzirrhose. Pro fünf Einheiten Zunahme BMI kam es zu einem adjustierten relativen Risiko für eine Leberzirrhose von $28 \%$.

Bei Frauen, die weniger als $70 \mathrm{~g} \mathrm{Al}$ kohol zu sich nahmen, betrug das absolute Risiko für eine Leberzirrhose pro 1000 Frauen im Lauf von fünf Jahren bei einem BMI zwischen 22,5 und 25 0,8 , bei einem $\mathrm{BMI}$ über 30 dagegen 1,0. Betrachtete man die Frauen mit einem wöchentlichen Alkoholkonsum von mehr als $150 \mathrm{~g}$ pro Woche, so errechneten sich die zugehörigen Risiken mit 2,7 bzw. 5,0 in den beiden BMIGruppen. Rechnerisch gesehen sind $42 \%$ der Fälle von Leberzirrhose und der Todesfälle an dieser Erkrankung dem Alkohol zu zuordnen, jedoch immerhin 17\% dem Übergewicht.

\section{Kommentar}

Im Vergleich zum Alkohol ist der Einfluss des Übergewichtes über eine Leberverfettung und Auftreten einer Steatohepatitis noch mäßig. Allerdings darf man nicht vergessen, dass das Phänomen des Übergewichts bei Frauen im mittleren Lebensalter wesentlich häufiger ist als ein schädlicher Alkoholkonsum. Insofern ist

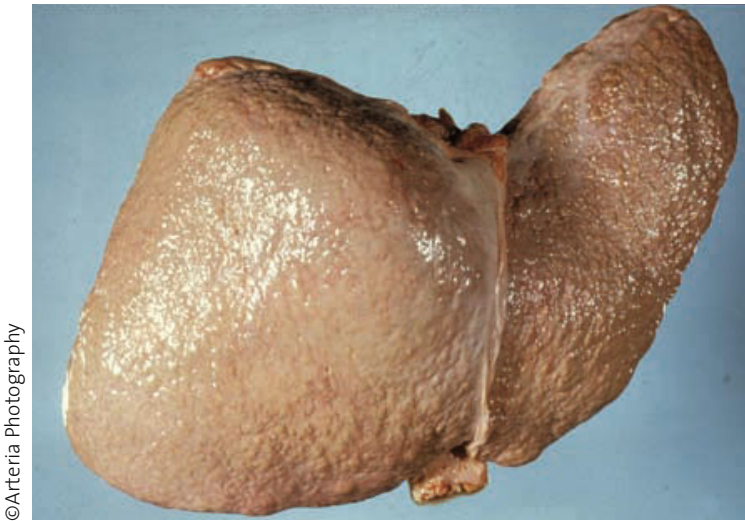

Kleinknotige Leberzirrhose: Nicht immer liegt's am übermäßigen Alkoholkonsum.

zu erwarten, dass die Fälle von Leberzirrhose in den kommenden Jahren - absolut betrachtet - erheblich zunehmen werden. Die Adipositas gilt bei den meisten Menschen noch vorwiegend als kosmetisches Problem. Fragt man nach den gesundheitlichen Folgen, so dürften die häufigsten Antworten Hypertonie, koronare Herzkrankheit und vielleicht degenerative Skelettveränderungen sein. An die Leberzirrhose denkt noch kaum jemand.

H. S. FüEßL =

- B. Liu et al.

(Korr. Bette Liu, MD Cancer Epidemiology Unit, University of Oxford, Oxford $\mathrm{OX}_{3} 7 \mathrm{LF}$, e-mail:Bette.Liu@ceu.ox.ac.uk oder bliu@ george.org.au): Body mass index and risk of liver cirrhosis in middle aged UK women: prospective study. Brit. Med. J. 2010;340:0912 